\title{
Morfologia comparativa de propágulos de Chrysophyllum amazonicum T. D. Penn. e Chrysophyllum prieurii A.D. Candolle ${ }^{1}$
}

\author{
Sheylla Fontes Pinto ${ }^{2 *}$, Maria da Glória Gonçalves de Melo², \\ Ângela Maria da Silva Mendes ${ }^{2}$
}

\begin{abstract}
RESUMO - O gênero Chrysophyllum possui cerca de 70 espécies. O estudo da morfologia possibilita diferenciar espécies do mesmo gênero. Com este trabalho objetivou-se comparar morfologicamente os propágulos de C. amazonicum e C. prieurii. Os frutos foram coletados de matrizes ocorrentes na base de extração petrolífera Geólogo Pedro de Moura, Coari, AM. Uma subamostra com 50 frutos e sementes foi selecionada aleatoriamente para a descrição morfológica. Para a caracterização do desenvolvimento da plântula foi semeada uma amostra de $4 \times 25$ sementes, em areia lavada e vermiculita (2:1). Os frutos são secos em C. amazonicum e carnosos em $C$. prieurii. As sementes diferenciam-se no formato e coloração dos cotilédones: obovados e esverdeados em C. amazonicum e oblongos e amarelados em C. prieurii. A germinação é epígea e o parâmetro de diferenciação nessa fase, é o formato do limbo cotiledonar, elíptico obovado em C. amazonicum e elíptico oblongo em C. prieurii. As plântulas, em ambas as espécies, são fanerocotiledonar com cotilédones foliáceos, que visualmente aparentam semelhança. Contudo em análise detalhada é possível distingui-las pela cor da raiz principal, pelo formato em corte transversal do epicótilo, e pelo formato do limbo do eofilo, lanceolado elíptico em C. amazonicum e lanceolado estreito elíptico em C. prieurii.
\end{abstract}

Termos para indexação: frutos, sementes, Sapotaceae, espécies florestais.

\section{Comparative morphology of propagules of Chrysophyllum amazonicum T. D. Penn. and Chrysophyllum prieurii A. D. Candolle}

\begin{abstract}
The genus Chrysophyllum has about 70 species and species of the same genus can be differentiated morphologically. The objective of this study was to compare the morphology of the propagules of $C$. amazonicum and C. prieurii. The fruits were collected from arrays at the Pedro de Moura oil extraction unit, Coari, Amazonas state. A sub-sample with 50 fruits and seeds was randomly selected for the morphological analysis. A sample of $4 \times 25$ seeds was sown in washed sand and vermiculite (2:1) to evaluate seedling development. The fruits of C. amazonicum are dry whereas those of $C$. prieurii are pulpous. The seed cotyledons have different shapes and colors: obovate and greenish in C. amazonicum and oblong and yellowish in C. prieurii. The germination is epigeal and the difference is in the format of the cotyledonal limbo: elliptical obovate in C. amazonicum and elliptical oblong in C. prieurii. The seedlings of both species are phanerocotyledonate with foliaceous cotyledons, that are visually similar. However, they may be distinguished by the color of the main root, the format in cross section of the epicotyle, and the format of the limbo of the eophyll: lanceolate elliptical (C. amazonicum) and lanceolate narrow elliptical (C. prieurii).
\end{abstract}

Index terms: fruits, seeds, Sapotaceae, forest species

\footnotetext{
${ }^{1}$ Submetido em 15/03/2011. Aceito para publicação em 30/11/2011.

${ }^{2}$ Departamento de Engenharia Florestal, Universidade do Estado do Amazonas (UEA), 69050-020 - Manaus, AM, Brasil.

*Autor para correspondência < sheyllafontes@hotmail.com>
} 


\section{Introdução}

A família Sapotaceae é pantropical com 53 gêneros e cerca de 1100 espécies, concentradas principalmente nas Américas, Ásia, na região do Pacífico e África (Monteiro et al., 2007). Os seus representantes são caracterizados por serem arbóreos ou arbustivos, e pela presença de látex, quase sempre presente no tronco, ramos e frutos, geralmente branco, raro amarelo (Monteiro et al., 2007). A família destaca-se por apresentar características de importância econômica, como a presença de laticíferos, a produção de frutos comestíveis (Pennington, 1990), além de serem fornecedoras de madeira de excelente qualidade (Pennington, 1990; Heywood, 1993).

No Brasil, Sapotaceae possui 11 gêneros, 221 espécies (95 endêmicas) e 32 subespécies (quatro endêmicas), conforme Carneiro e Almeida Jr. (2010). O gênero Chrysophyllum com cerca de 70 espécies em nível mundial (Judd et al., 1999), está representado no Brasil por 31 espécies (14 endêmicas) e oito subespécies (duas endêmicas), ou seja 44,3\% das espécies do gênero, sendo 22 espécies registradas para a região amazônica. Dentre estas estão Chrysophyllum amazonicum T. D. Penn. e C. prieurii A. D. C.

Chrysophyllum amazonicum T. D. Penn. popularmente designada de abiurana, (Ribeiro et al., 1999) é uma espécie arbórea de dossel que ocorre com frequência em floresta úmida inundável da Amazônia brasileira ao Peru, Colômbia e sul da Venezuela (Pennington, 2006); no Brasil pode ser encontrada nas regiões Norte (Roraima, Pará, Amazônia, Acre e Rondônia), Centro-Oeste (Mato Grosso) segundo Carneiro e Almeida Jr. (2010). Pode atingir $30 \mathrm{~m}$ de altura e $50 \mathrm{~cm}$ de diâmetro, com ritidoma amarronzado com leves fissuras avermelhadas, apresenta cheiro amendoado e exsuda látex leitoso branco (Pennington, 2006).

Chrysophyllum prieurii A. D. C. é uma espécie arbórea de dossel, que ocorre no Brasil, nos estados do Amapá, Amazonas e Pará (Roosmalen e Garcia, 2000), Acre e Maranhão (Carneiro e Almeida Jr., 2010), na Colômbia, Guianas, Peru, Venezuela (Roosmalen e Garcia, 2000) e Panamá (Ribeiro et al., 1999), pode atingir $40 \mathrm{~m}$ de altura e $120 \mathrm{~cm}$ de diâmetro, com ritidoma fissurado, de coloração marrom avermelhado, exsuda pouco látex de cor branca ou amarela. É frequente em floresta úmida de terra firme, também é encontrada em floresta de savana. Essa espécie apresenta várias designações populares como abiurana, abiú, mocambo, castanha-vermelha, massaranduba (Roosmalen e Garcia, 2000), abiu-de-cascafina, abiurana-maçaranduba, abiurana-vermelha, abiuranaquadrada, pau-doce (Ibama, 2009).
A morfologia tem sido o principal critério adotado para o reconhecimento de espécies florestais. De acordo com o conceito da morfologia, as espécies vegetais pertencem a grupos de organismos similares que são morfologicamente distintos entre si (Font-Quer, 1963). No entanto é possível que espécies distintas apresentem semelhanças entre si.

As espécies $C$. amazonicum e $C$. prieurii são similares morfologicamente, no que se referem as suas sementes e plântulas nos estádios iniciais de desenvolvimento, e poucas são as informações científicas referentes aos conhecimentos básicos sobre suas sementes e o processo de reconhecimento e desenvolvimento das mesmas em viveiro. De acordo com Fernandes (1996), a morfologia oferece base para a identificação e para a classificação dos vegetais, por abranger caracteres de pronta e fácil interpretação.

Estudos da morfologia externa e interna das unidades de dispersão são importantes para a identificação das plantas das quais estas foram originadas, fornece informações sobre o estágio de maturação das sementes, possibilitando a definição da época de colheita (Van Der Pijl, 1982), e está diretamente relacionada com a regeneração natural, determinando o comportamento das espécies durante a dispersão, a formação do banco de sementes e de plântulas, a própria germinação e a longevidade (Ressel et al., 2004).

A morfologia do desenvolvimento de plântulas pode revelar aspectos sobre a história ecológica e evolutiva dos mais variados grupos de plantas, além de fornecer várias características para sua identificação (Duke, 1969; AmoRodrigues, 1979; Ng, 1978; Ibarra-Manriquez et al., 2001). Além disso, pode subsidiar os estudos taxonômicos, pois permite o conhecimento das estruturas essenciais da plântula ao longo do seu desenvolvimento, possibilitando a caracterização da espécie (Paoli e Santos, 1998). Também auxiliam no manejo, na conservação e na reconstituição de florestas tropicais, pois possibilitam a identificação dos táxons em suas fases juvenis (Kodama e Sartori, 2007).

Devido à importância de estudos morfológicos de espécies florestais nativas e considerando a semelhança morfológica entre as sementes e plântulas das espécies em questão, o objetivo neste estudo foi descrever e ilustrar os aspectos morfológicos dos frutos, das sementes e das plântulas nos estádios iniciais de desenvolvimento de $C$. amazonicum e C. prieurii.

\section{Material e Métodos}

Os frutos das espécies em estudo foram coletados em abril de 2008, de cinco indivíduos arbóreos, de cada espécie, 
distantes $100 \mathrm{~m}$ entre si ocorrentes em floresta primária de terra-firme na base de extração petrolífera Geólogo Pedro de Moura (430’ $\left.\mathrm{S} / 64^{\circ} 30^{\prime} \mathrm{W}\right)$. A base operacional, gerenciada pela Petrobrás, é localizada na bacia do rio Urucu, no município de Coari, no estado do Amazonas. A região é caracterizada

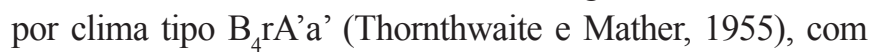
precipitação média anual de $66,1 \%$ e temperatura entre 25 e $26^{\circ} \mathrm{C}$ (Lima et al., 2008). O material botânico foi identificado no Herbário do Instituto Nacional de Pesquisas da Amazônia (INPA) e os estudos realizados no Laboratório e Viveiro de Sementes Florestais da Escola Superior de Tecnologia (EST), da Universidade do Estado do Amazonas (UEA).

Para a caracterização morfológica dos frutos e das sementes foram utilizadas 50 unidades de cada espécie, escolhidas aleatoriamente, após mistura e homogeneização dos lotes. Na mesma amostra de frutos, foi realizada a abertura dos mesmos para registro do número de sementes. As observações foram feitas com auxílio de lupa de mesa e estereomicroscópio binocular, sendo os caracteres morfológicos fotografados em lupa adaptada com máquina fotográfica digital. As mensurações de tamanho foram efetuadas com auxílio de paquímetro digital e o peso de massa fresca com balança analítica.

No estudo dos frutos foram considerados tipo, coloração, textura, consistência e indumento do exocarpo, mesocarpo e endocarpo e, deiscência. No estudo da semente, os parâmetros empregados foram forma, borda, tipo, coloração, consistência e textura dos tegumentos, posição do hilo e da micrópila, e embrião quanto ao tipo e forma. A metodologia e terminologia empregadas para a descrição de fruto e sementes foram baseadas em (FontQuer,1963; Lawrence, 1970; Radford et al.,1974; Roth, 1977; Beltrati, 1992; Joly, 1993; Vidal e Vidal, 1995; Barroso et al.,1999; Camargo et al., 2008).

Para a caracterização do tipo de germinação e para o acompanhamento do desenvolvimento da plântula, foram semeadas 100 sementes, distribuídas em quatro repetições de 25 , em bandejas de plástico $(80 \times 40 \times 20 \mathrm{~cm})$, contendo um substrato composto por areia lavada e vermiculita (2:1), mantidas em viveiro sob condições ambientais, cobertas por sombrite $30 \%$ e irrigadas diariamente. As contagens foram realizadas diariamente, computando-se o número de sementes germinadas. Ao final do período germinativo de cada espécie obteve-se a porcentagem de germinação.

Foram consideradas duas fases para o acompanhamento e descrição do desenvolvimento da plântula. A primeira fase, considerada germinação, o período compreendido entre a protrusão da raiz primária até total expansão dos cotilédones, conforme a classificação proposta por Miquel (1987) para espécies com cotilédones foliáceos expostos e acima do solo; a segunda fase, caracterizada como plântula, o material vegetativo que apresentava o eofilo completamente formado e expandido, concordando com Souza (2003). Os elementos descritos e ilustrados foram: raiz (principal e secundária), coleto, hipocótilo, cotilédones, epicótilo, eofilos e protofilos.

As descrições foram feitas de acordo com o surgimento das estruturas em cada estádio de desenvolvimento. Os caracteres morfológicos foram ilustrados, sendo as descrições feitas a olho nu ou com auxílio de estereomicroscópio. Estruturas vegetativas representantes das diferentes fases de desenvolvimento e da plântula foram fixadas em FAA (etanol 96\%, ácido acético glacial e formaldeído (formol) 37-44\%) por 24 horas, e posteriormente conservadas em álcool etílico $70 \%$.

A terminologia empregada está de acordo com (FontQuer,1963; Ng, 1978; Ribeiro et al., 1999; Gonçalves e Lorenzi, 2007; Camargo et al., 2008).

\section{Resultados e Discussão}

\section{Morfologia do fruto}

O fruto é estenocárpico, do tipo bacoide, indeiscente, de cor alaranjada (maduro), com forma ovata, ápice acuminado e base arredondada em C. amazonicum e globosa, ápice e base arredondados em C. prieurii (Figura 1A, D). Segundo Barroso et al. (1999), o fruto do tipo bacoide é muito característico na família Sapotaceae e nesta categoria incluem-se os frutos indeiscentes, carnosos, com pericarpo de pouco a muito espessado e endocarpo constituído da epiderme interna, esclereificada ou coriácea.

As espécies diferem entre si por apresentarem frutos secos em C. amazonicum e carnosos em C. prieurii. Em alguns subtipos de frutos bacoides, a polpa se desenvolve abundantemente, originada da multiplicação das células das placentas ou da porção interna, na região do endocarpo; em outros, apenas a parede do fruto é mais ou menos carnosa, e a semente não é envolvida por polpa (Barroso et al., 1999).

O pedicelo é cilíndrico em corte transversal, lenhoso, espesso, de coloração marrom clara, a superfície é opaca, glabra com fissuras longitudinais em C. amazonicum e rugosa em $C$. prieurii (Figura 1A, D). A espécie $C$. amazonicum apresenta cálice persistente com cinco sépalas. O cálice persistente também foi observado nos frutos de $C$. gonocarpum por (Felippi et al., 2008). 


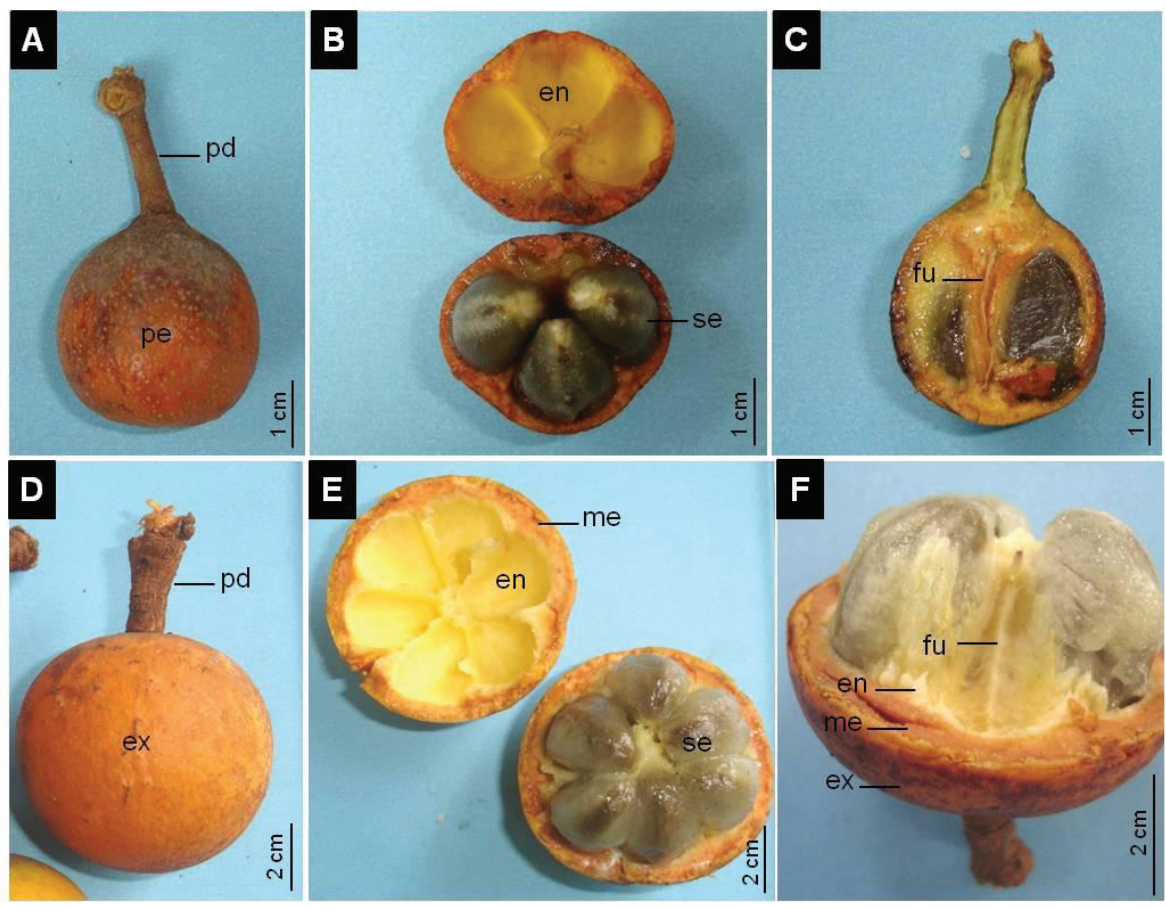

Figura 1. Morfologia do fruto: (a-c) Chrysophyllum amazonicum e (d-f) Chrysophyllum prieurii. A, D - aspecto da morfologia externa; B, E - corte transversal, evidenciando as diferentes camadas; C, F- detalhe do funículo. en - endocarpo, ex - exocarpo, fu - funículo, me - mesocarpo, pe - pericarpo, pd - pedicelo, se - semente.

O pericarpo maduro de C. amazonicum é seco, crasso, com superfície externa sem brilho, com lenticelas salientes, de coloração castanha, internamente é septado, formando três cavidades seminais lisas e brilhantes, de cor amarela (Figura 1A, B). O exocarpo maduro de C. prieurii é cartáceo, com superfície opaca, lisa, de coloração laranja amarelada, com pequenas machas pretas (Figura 1D).

O mesocarpo de C. prieurii é carnoso, suculento, de coloração laranja (Figura 1E) e apesar de apresentar-se carnoso, o mesmo não se constitui em polpa na referida espécie.

$\mathrm{O}$ endocarpo em ambas as espécies é mucilaginoso e gelatinoso, de cor amarela hialina; a porção gelatinosa permanece aderida à semente (Figura 1B, E). Em C. prieurii o endocarpo internamente é septado com cavidades seminais lisas e brilhantes, de coloração amarela esbranquiçada (Figura 1E).

$\mathrm{Na}$ região da placentação observa-se o funículo membranoso, longo, delgado, linear, curvado na extremidade, de cor amarela esbranquiçada em C. amazonicum e amarela em C. prieurii (Figura 1C, F).

O comprimento médio do fruto de $C$. amazonicum é 2,8 $( \pm 1,49) \mathrm{cm}$, com diâmetro de $2,6( \pm 2,41) \mathrm{cm}$ e peso médio de massa fresca de $10,43( \pm 2,63)$ g. O número de sementes por fruto variou de 1 a $5( \pm 0,97)$, com maior frequência de três sementes. Para C. prieurii, o comprimento médio é 4,4( $\pm 1,92)$ $\mathrm{cm}$, com diâmetro de $4,7( \pm 2,09)$ e peso médio de massa fresca de $54,27( \pm 7,91)$ g. O número de sementes variou de 2 a 5 $( \pm 0,93)$ por fruto, com maior frequência de quatro.

\section{Morfologia da semente}

Ambas as espécies não apresentaram variação na forma das sementes, portanto são estenospérmicas, de forma obovada em C. amazonicum por apresentar ápice arredondado e base aguda e forma oblonga em C. prieurii, pois as extremidades são agudas (Figura 2A, G).

O tegumento externo (testa) é pétreo em C. amazonicum e crasso em C. prieurii, superfície glabra, opaca, de coloração castanha, rugosa em C. amazonicum e levemente rugosa em C. prieurii (Figura 2A, G).

A região hilar é lateral, com hilo plano e oblanceolado em C. amazonicum e lanceolado em C. prieurii, estendendose do ápice a base da semente com bordadura saliente, de coloração castanha em tom mais claro que a testa (Figura 2B, H). A micrópila é punctiforme, depressa, castanha clara, de difícil visualização em ambas as espécies (Figura 2C, I). As sementes da família Sapotaceae são facilmente reconhecíveis, devido à testa brilhante e escura e ao hilo particular (Barroso et al., 1999). Corner (1976) afirmou 
que o óvulo das Sapotaceae parece ter perdido seu funículo nos gêneros mais evoluídos e, em se tornando séssil, desenvolveu um campo maior de fixação, resultando no hilo linear ou expandido.
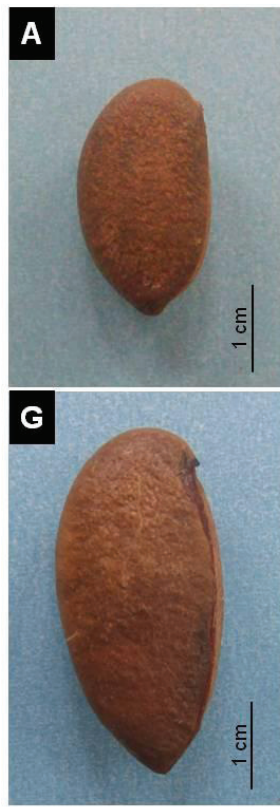
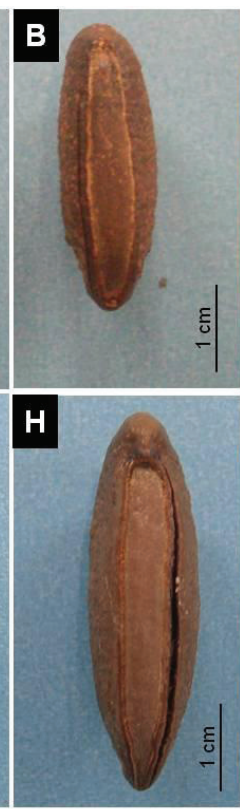
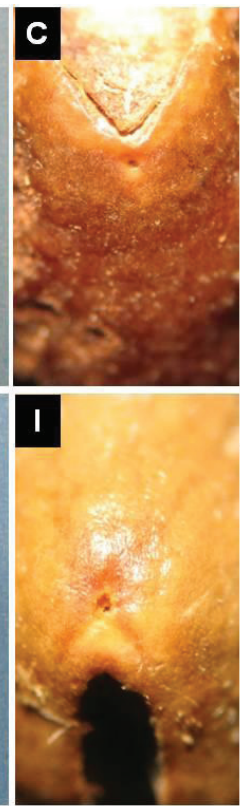
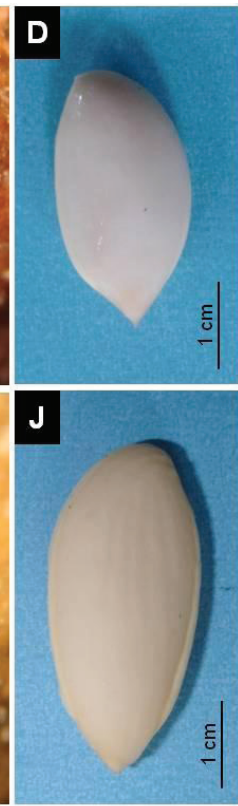
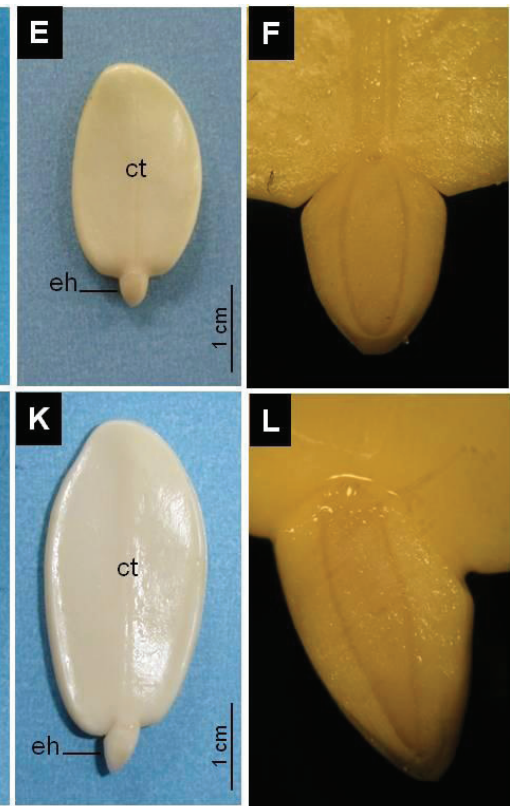

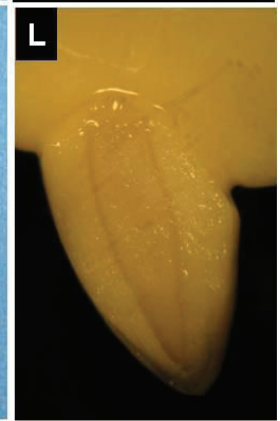

Figura 2. Morfologia da semente: (a-f) Chrysophyllum amazonicum e (g-1) Chrysophyllum prieurii. A, G - aspecto da morfologia externa; B, H - detalhe do hilo lateral; C, I - detalhe da micrópila; D, J - endosperma envolvendo o embrião; E, K - embrião foliáceo; F, L - corte transversal do eixo hipocótilo-radícula, evidenciando plúmula indiferenciada. ct - cotilédone, eh - eixo hipocótilo-radícula.

O tegumento interno em ambas as espécies é papiráceo, delgado, de cor castanha. O endosperma é contínuo, espesso, seco e membranoso (hidratado), de cor branca (Figura 2D, J).

O embrião é axial, espatulado, de cor esverdeada em $C$. amazonicum e amarelada em $C$. prieurii, com cotilédones foliáceos, dominantes e entalhados com a radícula exposta (Figura 2E, K). Os cotilédones apresentam as lâminas retas com as faces superiores em contato, e nervuras evidentes na face abaxial. As espécies estudadas são diferenciadas por apresentarem cotilédones espessos, de forma obovada, ápice levemente obtuso, margem inteira e base levemente cordada, de cor esverdeada em C. amazonicum e delgados, de forma oblonga, ápice obtuso, margem inteira e base cordada, de coloração amarelada em C. prieurii (Figura 2E, K). O eixo hipocótilo-radícula é exposto às folhas cotiledonares, espesso, reto em C. amazonicum e oblíquo em C. prieurii. Apresentam forma obcônica e coloração branca em C. amazonicum e cuneiforme e coloração amarelada em $C$. prieurii. A plúmula é indiferenciada em ambas as espécies (Figura 2F, L).

O comprimento médio da semente de $C$. amazonicum é $2,1( \pm 1,25) \mathrm{cm}$, com largura e espessura médias de 1,1 $( \pm 0,59)$ e $7,1( \pm 0,50) \mathrm{cm}$, respectivamente e, peso médio de massa fresca de 0,92 $( \pm 0,13)$ g. Para $C$. prieurii, o comprimento médio é $2,9( \pm 1,72) \mathrm{cm}$, com largura e espessura médias de $1,4( \pm 0,72)$ e $9,24( \pm 0,50) \mathrm{cm}$, respectivamente e, peso médio de massa fresca de 2,0 $( \pm 0,25) \mathrm{g}$. As dimensões das sementes também são parâmetros que diferem nas espécies estudadas.

\section{Morfologia do processo de germinação}

O processo germinativo foi relativamente rápido, iniciando entre seis e nove dias após a semeadura (DAS) e término de 22 DAS para $C$. amazonicum e 19 DAS em $C$. prieurii, com porcentagem final de sementes germinadas de $77 \%$ em C. amazonicum e 100\% em C. prieurii.

A germinação em ambas as espécies é epígea, com a protrusão da raiz primária rompendo o tegumento na região hilar (Figura 3A, B).

Inicialmente a raiz primária apresenta-se herbácea, cilíndrica, curta, reta, com "tufos" de tricomas curtos e hialinos distribuídos espaçadamente em C. amazonicum (Figura 3A $\mathrm{A}_{1}$ ) e glabra em C. prieurii (Figura 3B $\mathrm{B}_{1}$ ); com o desenvolvimento torna-

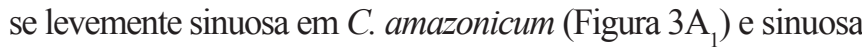
com tricomas curtos e hialinos, distribuídos irregularmente em C. prieurii (Figura $3 \mathrm{~B}_{1}$ ). 


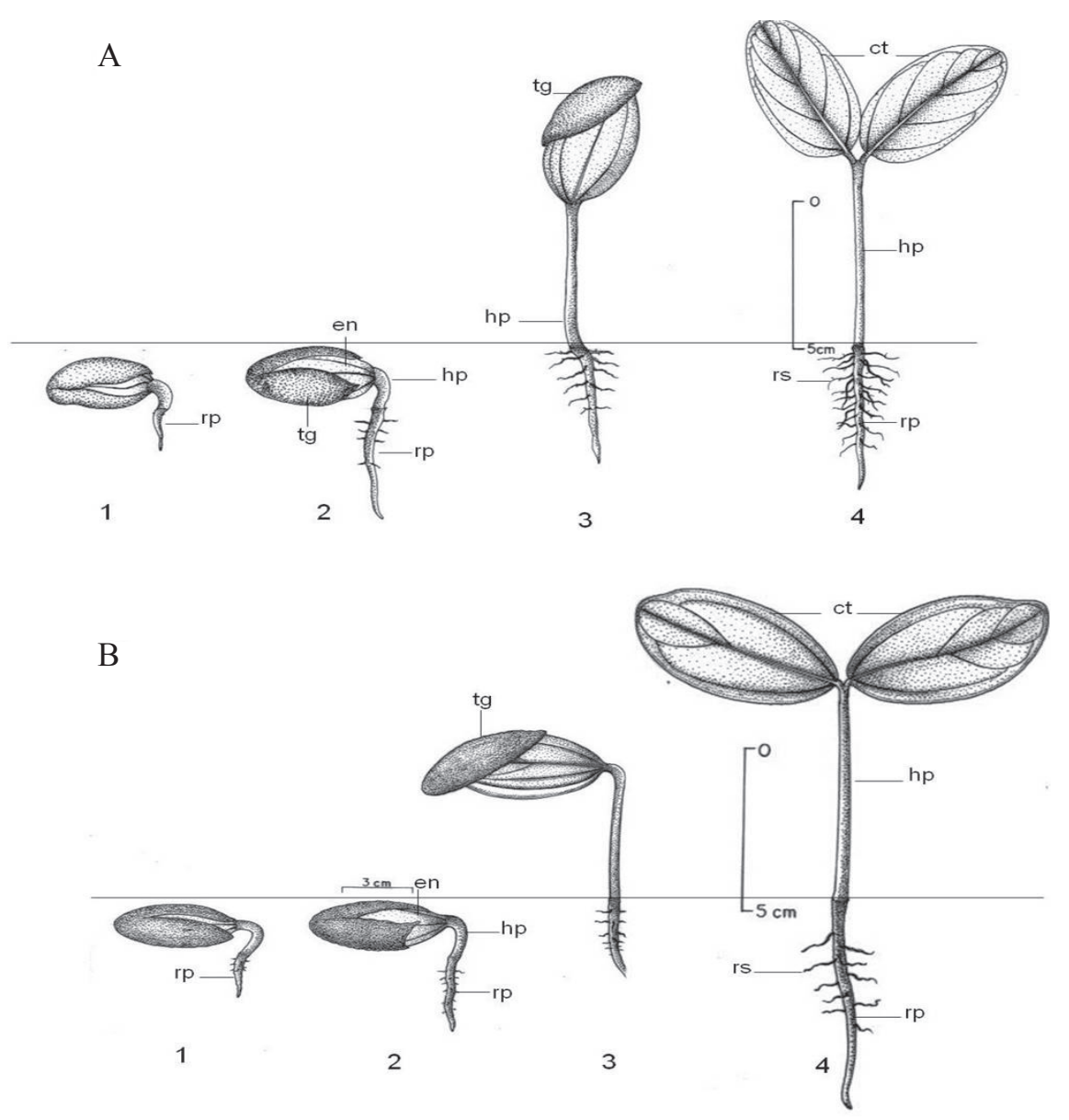

Figura 3. Morfologia da germinação: A - Chrysophyllum amazonicum e B - Chrysophyllum prieurii. 1 - Emissão da raiz primária; 2 - Alongamento da raiz primária; 3 - Elevação do hipocótilo acima do solo; 4 - Abertura dos cotilédones foliáceos. ct - cotilédone, en - endosperma, hp - hipocótilo, rp - raiz primária, rs - raiz secundária, $\operatorname{tg}$ - tegumento.

O coleto é evidenciado pela cor verde esbranquiçada em ambas as espécies (Figura $3 \mathrm{~A}_{3}, \mathrm{~B}_{3}$ ). $\mathrm{O}$ hipocótilo elevase acima do solo em forma de gancho no $16^{\circ}$ DAS em C. amazonicum e no $11^{\circ}$ em C. prieurii. Segundo Souza (2003), em muitas plântulas epígeas, no estágio inicial de desenvolvimento, o hipocótilo apresenta aspecto de alça ou gancho, mantendo os cotilédones aéreos, mais próximos à superfície do solo. Posteriormente o hipocótilo torna-se reto aos 19 DAS em C. amazonicum (Figura $3 \mathrm{~A}_{4}$ ) e aos 17 DAS em C. prieurii (Figura $3 \mathrm{~B}_{4}$ ), elevando o tegumento da semente. Nesta fase apresenta-se herbáceo, cilíndrico, espesso, glabro, coloração verde clara, com comprimento médio de 4,6 $( \pm 0,72) \mathrm{cm}$ em $C$. amazonicum, e de 6,5 $( \pm 1,04) \mathrm{cm}$ em $C$. prieurii.

Os cotilédones foliáceos são liberados pela região hilar da semente, que se desprende como uma cápsula, após a total exaustão do endosperma, aos 22 DAS em $C$.

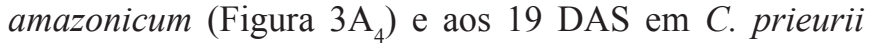
(Figura $3 \mathrm{~B}_{4}$ ). Os pecíolos cotiledonares são ascendentes, achatados, reduzidos, glabros, de coloração verde musgo em ambas as espécies.

Os cotilédones são isofilos, opostos, glabros, de coloração verde musgo, com prefolheação valvar e venação uninérvea evidente na face adaxial. O limbo cotiledonar apresenta forma elíptica obovada em C. amazonicum e elíptica oblonga em $C$. prieurii, o ápice é obtuso, a margem inteira e a base aguda em ambas as espécies. $\mathrm{O}$ formato do limbo cotiledonar também se constitui em um parâmetro para diferenciar as espécies.

Finalizando o desenvolvimento no $26^{\circ}$ dia em $C$. amazonicum e no $24^{\circ}$ dia em $C$. prieurii surge o epicótilo e se inicia um processo de lignificação do hipocótilo, que se modifica de herbáceo para sublenhoso, e no $30^{\circ}$ dia em ambas as espécies, surge o eofilo. 


\section{Morfologia da plântula}

A plântula do tipo fanerocotiledonar está completamente formada aos 43 dias em C. amazonicum
(Figura 4A) e 39 dias em C. prieurii (Figura 4B). Visualmente, sem análise detalhada, as plântulas das duas espécies são semelhantes.

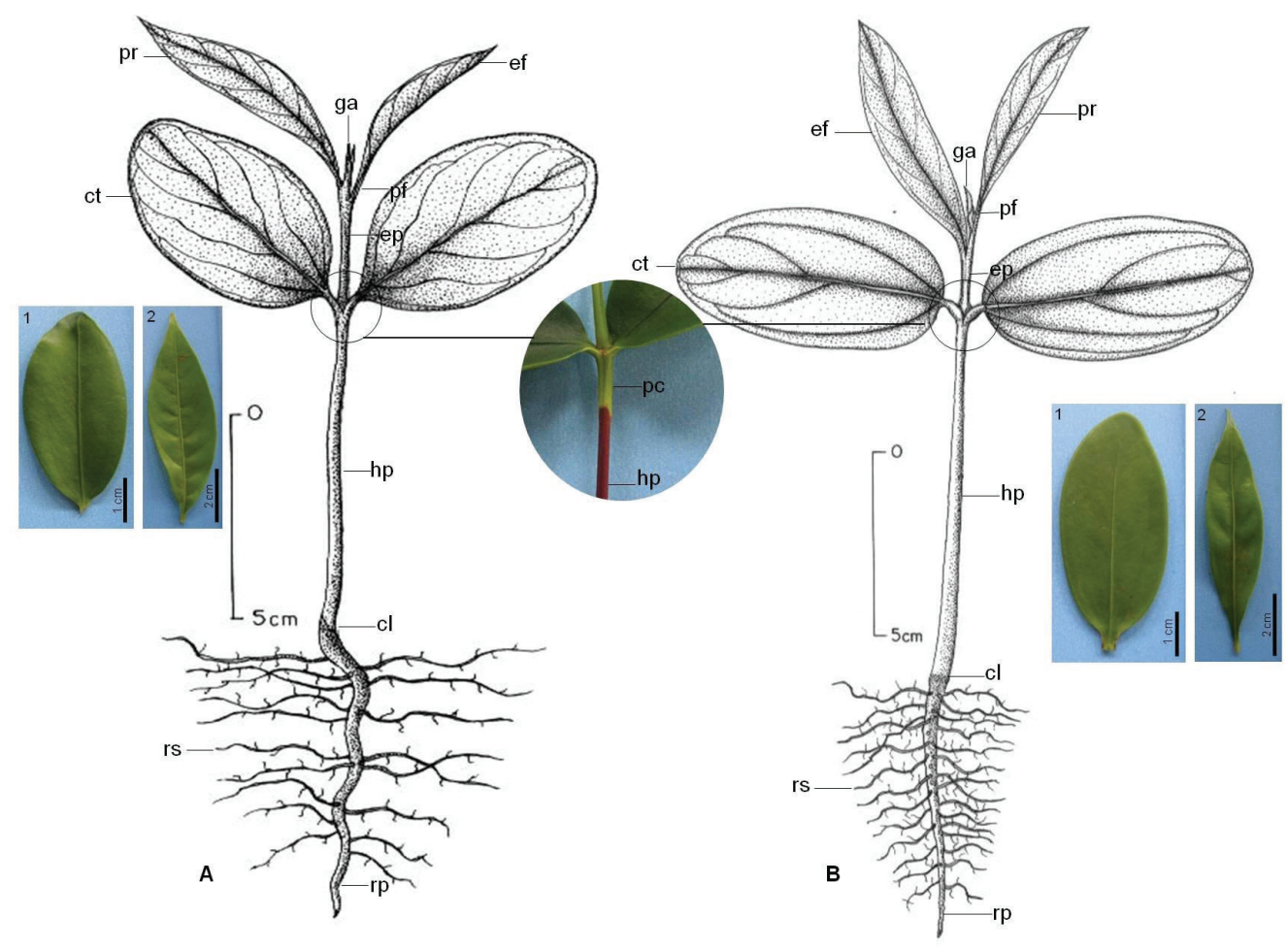

Figura 4. Morfologia da plântula: A - Chrysophyllum amazonicum e B - Chrysophyllum prieurii. 1 - forma do limbo cotiledonar; 2 - forma do limbo foliar (eofilo e protofilo). cl - coleto, ct - cotilédone, ef - eofilo, ep - epicótilo, ga - gema apical, hp - hipocótilo, pc - pecíolo cotiledonar, pf - pecíolo foliar, pr - protofilo, $\mathrm{rp}$ - raiz primária, rs - raiz secundária.

A raiz principal é axial, cilíndrica, espessa, sinuosa, herbácea (ápice) e sublenhosa (base), esbranquiçada (ápice) e marrom claro (base), com "tufos" de tricomas hialinos próximos e abaixo das raízes secundárias em C. amazonicum e, herbácea, de cor esbranquiçada, com raros tricomas hialinos em C. prieurii. Apenas a cor da raiz principal e a distribuição dos tricomas, diferem nas espécies estudadas.

As raízes secundárias concorrem em comprimento com a principal e são herbáceas, delgadas, sinuosas, esbranquiçadas, pouco ramificadas, regularmente distribuídas, com raros tricomas semelhantes aos da raiz principal em C. amazonicum e glabras em C. prieurii.

$\mathrm{O}$ coleto assim como observado durante $\mathrm{o}$ desenvolvimento, é evidenciado apenas pela cor esbranquiçada em ambas as espécies.
O hipocótilo é sublenhoso, de forma cilíndrica, reto, espesso, glabro, de cor marrom clara, mediano em $C$. amazonicum e longo, com lenticelas levemente salientes em C. prieurii.

Os pecíolos cotiledonares em ambas as espécies apresentam-se soldados em torno do hipocótilo, são ascendentes, longos, glabros, de cor verde, distintos pela cor e pelo tecido herbáceo (Figura 4). Os cotilédones foliáceos são persistentes e, apresentam-se opostos, isofilos, glabros, de coloração verde musgo, com limbo elíptico obovado em C. amazonicum (Figura $4 \mathrm{~A}_{1}$ ) e elíptico oblongo em C. prieurii (Figura 4B $_{1}$. Segundo Vogel (1980), cotilédones foliáceos são frequentemente delgados, verdes e fotossintetizantes. Plântulas fanero-epígeo-foliáceo apresentam maior distribuição entre os grupos das pioneiras e das clímax exigentes de luz, o que corresponde à estratégia 
das espécies em seus estágios sucessionais iniciais (Ressel et al., 2004). Estes grupos tendem a crescer rapidamente para competir por espaço e luz (Ng, 1978) e, neste caso, cotilédones prontamente fotossintetizantes, significam uma vantagem adicional.

O epicótilo é herbáceo, curto, reto, de cor verde, com tricomas longos e amarronzados, em corte transversal é elíptico em C. amazonicum e cilíndrico em C. prieurii.

O pecíolo foliar é mediano, de coloração verde clara, levemente acanalado e delgado em C. amazonicum e cilíndrico, levemente espesso e com tricomas hialinos e adpressos em C. prieurii.

O eofilo é uma folha simples, de cor verde, com prefolheação conduplicada e nervação eucampidódroma em ambas as espécies.

O limbo foliar de C. amazonicum é lanceolado elíptico, com ápice acuminado, margem inteira e base atenuada (Figura 4A $\mathrm{A}_{2}$ ), e lanceolado estreito elíptico, com ápice e base atenuados e margem inteira em C. prieurii (Figura $\left.4 \mathrm{~B}_{2}\right)$.

Na lâmina foliar e nas nervuras de ambas as espécies ocorrem tricomas, sendo longos, eretos e amarronzados em C. amazonicum e hialinos e adpressos em C. prieurii.

O primeiro protofilo é uma folha simples, semelhante ao eofilo e a filotaxia é alterna em ambas as espécies.

As espécies estudadas apresentam semelhanças na fase de plântula que podem dificultar a identificação das mesmas em campo, no período de regeneração natural. No entanto com o presente estudo foi possível constatar parâmetros de diferenciação entre as espécies, sendo facilmente distintas a forma do limbo cotiledonar e eofilar.

\section{Conclusões}

Os frutos das espécies em estudo são notoriamente distintos: em C. amazonicum são secos com forma ovata, enquanto que em $C$. prieurii são carnosos com forma globosa.

As sementes são distintas pela forma e dimensões: em $C$. amazonicum são obovadas e medem em média $2,1( \pm 1,25)$ cm de comprimento, e em C. prieurii são oblongas e medem $2,9( \pm 1,72) \mathrm{cm}$.

Na fase de germinação o formato do limbo cotiledonar constitui o parâmetro de diferenciação entre as espécies, sendo elíptico obovado em C. amazonicum e elíptico oblongo em $C$. prieurii.

As plântulas são distintas pelo formato do limbo eofilar: lanceolado elíptico em C. amazonicum e lanceolado estreito elíptico em C. prieurii.

\section{Agradecimentos}

À FINEP/MCT e a Petróleo Brasileiro S/A, pelo apoio financeiro através do programa de Ciência e Tecnologia do Petróleo (CTPETRO). Ao CNPq, pela concessão da bolsa DTI à primeira autora. Ao Antônio Natalino C. Mota (coletor), pela aquisição dos frutos. À equipe do SMS, Meio Ambiente da BOGPM, pelo apoio nas atividades de pesquisa.

\section{Referências}

AMO-RODRIGUES, S. Clave para plántulas y estados juveniles de espécies primarias de una selva alta perennifolia em Veracruz, México. Biotica, v.42, p.59-108, 1979.

BARROSO, G.M.; MORIM, M.P. PEIXOTO, A.L.; ICHASO, C.L.F. Frutos e sementes: morfologia aplicada à sistemática de dicotiledôneas. Viçosa: UFV, 1999. 443p.

BELTRATI, C.M. Morfologia e anatomia de sementes. Rio Claro, SP: UNESP, 1992. 108p.

CAMARGO, J.L.C.; FERRAZ, I.D.K.; MESQUITA, M.R.; SANTOS, B.A.; BRUM, H.D. Guia de propágulos e plântulas da Amazônia. Manaus: INPA, 2008. 168p.

CARNEIRO, C.E.; ALMEIDA, E.B. Sapotaceae. In. FORZZA et al. (Org.). Catálogo de plantas e fungos do Brasil. v.2. Rio de Janeiro: Instituto de Pesquisas Jardim Botânico do Rio de Janeiro, 2010. v.2., p.1621-1629.

CORNER, E.J.H. The seeds of dicotyledons. Cambridge: University Press, 1976. v.2. 564p.

DUKE, J.A. On tropical tree seedlings, systems and systematic. Annals of the Missouri Botanical Garden, v.56, n.2, p.125-161, 1969. http:// www.biodiversitylibrary.org/item/65870\#page/132/mode/1up

FELIPPI, M.; GROSSI, F.; NOGUEIRA, A.C.; KUNIYOSHI, Y.S. Fenologia e germinação de sementes de aguai, Chrysophyllum gonocarpum (Mart. \& Eichl.) Engl. Floresta, v.38, n.2, p.229-243, 2008. http://ojs.c3sl.ufpr.br/ojs2/index.php/floresta/article/view/11618/8153

FERNANDES, A. Compêndio botânico: diversificação-taxionomia. Fortaleza: UFC, 1996.144p.

FONT-QUER, P. Dicionário de botânica. Barcelona: Labor S.A., 1963. $1244 \mathrm{p}$.

GONÇALVES, E.G.; LORENZI, H. Morfologia vegetal: organografia e dicionário ilustrado de morfologia das plantas vasculares. Nova Odessa: PLANTARUM, 2007. 416p.

HEYWOOD, V.H. Flowering of the world. London: B.T. Bastford Ltda, 1993. 335p. 
IBAMA. Instituto Brasileiro do Meio Ambiente e dos Recursos Naturais Renováveis. Madeiras Brasileiras. Banco de dados eletrônico. http:// www.ibama.gov.br/Ipf/madeira/pesquisa. Acesso em: 12 set. 2009.

IBARRA- MANRÍQUEZ, G.; RAMOS, M.M.; OYAMA, K. Seedling functional types in a lowland rain Forest in Mexico. American Journal of Botany, v.88, p.1801-1812, 2001. http://www.amjbot.org/ content/88/10/1801.full.pdf + html

JOLY, A.B. Botânica: introdução à taxonomia vegetal. São Paulo: NACIONAL, 1993. 777p.

JUDD, W.S.; CAMPBELL, C.S.; KELLOG, E.A.; STEVENS, P.F. Pant systematics - a phylogenetic approach. United States American: SINAUER ASSOCIATES, 1999. 464p.

KODAMA, M.T.; SARTORI, A.L.B. Caracterização morfológica de plântulas de Hymenaea stigonocarpa var. stigonocarpa Mart. ex. Hayne, H. stigonocarpa Hayne var. brevipetiolata N. Mattos e H. courbaril L. Revista Brasileira de Biociência, v.5, n.1, p.660-662, 2007. http://www6. ufrgs.br/seerbio/ojs/index.php/rbb/article/view/675/565

LAWRENCE, G.H.M. Taxonomy of vascular plants. New York: The Macmillan, 1970. 823p.

LIMA, S.O.F. et al. Biodiversidade na Província Petrolifera de Urucu. Rio de Janeiro: PETROBRAS/ CENPES, 2008. 194p.

MIQUEL, S. Morphologie fonctionnelle de plantules d'espèces forestières du Gabon. Adansonia. Bulletin du Muséum National d'Histoire Naturelle, s.4, sect. B, v.9, p.101-121, 1987.

MONTEIRO, M.H.D.A.; NEVES, L.J.; ANDREATA, R.H.P. Levantamento e distribuição das espécies de Pouteria Aubl. (Sapotaceae) no estado do Rio de Janeiro. Revista Brasileira de Biociências, v.5, n.2, p.369-371, 2007. http://www6.ufrgs.br/seerbio/ojs/index.php/rbb/article/ view/334/440

NG, F.S.P. Strategies of establishment in Malayan Forest trees. In: TOMLINSON, P.B.P.; ZIMMERMANN, M.H. (eds.) Tropical trees as living systems. London: Cambrigde University Prees, 1978. p.129-162.

PAOLI, A.A.S.; SANTOS, M.R.O. Caracterização morfológica de frutos, sementes e plântulas de Sapindus saponaria L. (Sapindaceae). Revista Brasileira de Sementes, v.20, n.2, p.385-391, 1998.
PENNINGTON, T.D. Flora da Reserva Ducke, Amazonas, Brasil: Sapotaceae. Rodriguesia, v.57, n.2, p.251-363, 2006. http://rodriguesia. jbrj.gov.br/rodrig57_2/sapotaceae6.pdf

PENNINGTON, T.D. Flora Neotropica, 52 Sapotaceae. New York: BOTANICAL GARDEN, 1990.

RADFORD, A.E.; DICKISON, W.C.; MASSEY, J.R.; BELL, C.R. Vascular plants sistematics. New York: Harper and Row, 1974. 877p.

RESSEL, K; GUILHERME, F.A.G.; SCHIAVINI, I.; OLIVEIRA, P.E. Ecologia morfofuncional de plântulas de espécies arbóreas da Estação Ecológica do Panga, Uberlândia, Minas Gerais. Revista Brasileira de Botânica, v.27, n.2, p.311-323, 2004. http://www.scielo.br/pdf/rbb/ v27n2/v27n2a10.pdf

RIBEIRO, J.E.L.S.; HOPKINS, M.J.G.; VICENTINI, A.; SOTHERS, C.A.; COSTA, M.A.S.; BRITO, J.M.; SOUZA, M.A.D.; MARTINS, L.H.; LOHMANN, L.G.; ASSUNCAO, P.A.C.L.; PEREIRA, E.C.; SILVA, C.F.; MESQUITA, M.R.; PROCOPIO, L.C. Flora da Reserva Ducke: guia de identificação das plantas vasculares de uma floresta de terra-firme na Amazônia Central. Manaus, AM: INPA, 1999. 816p.

ROOSMALEN, M.G.M.V.; GARCIA, O.M.C.G. Fruits of the Amazonian Forest. Part II: Sapotaceae. Acta Amazonica, v.30, n.2, p.187-290, 2000. http://acta.inpa.gov.br/fasciculos/30-2/PDF/v30n2a03.pdf

ROTH, I. Fruits of angioperms: encyclopedia of plant anatomy. Berlin: Gebruder Borntraeger, 1977. 676p.

SOUZA, L.A. Morfologia e anatomia vegetal: célula, tecido, órgãos e plântulas. Ponta Grossa: UFPE, 2003. 279p.

THORNTHWAITE, C.W.; MATHER, R.J. The water balance. New Jersey: Laboratory of Climatology, 1955. v.8, p.104.

VAN DER PIJL, L. Principles of dispersal in higher plants. Berlim: Springer-Verlag, 1982. 3.ed. 214p.

VIDAL, V.N.; VIDAL, M.R.R. Botânica - organografia. Viçosa, MG: UFV, 1995. 114p.

VOGEL, E.F. Seedlings of dicotyledons: structure, development, types and descriptions of 150 woody Malesian taxa. Centre for Publishing and Documentation: Wageningen, 1980. 